\title{
Cerebral Venous Thrombosis in a Patient Who Is Regarded to Have Headache Due to Spinal Anesthetic Intervention
}

\author{
Spinal Anestezi Girişimine Bağlı Baş Ağrısı Olduğu Düşünülen Bir Hastada \\ Serebral VenözTromboz
}

Fatma Doğanay ${ }^{1}$, Ferudun Koyuncu ${ }^{2}$

'Department of Neurology, Mevlana University Faculty of Medicine, Konya, Turkey 2Department of Emergency Medicine, Mevlana University Faculty of Medicine, Konya, Turkey

\begin{abstract}
Introduction: Headache after spinal anesthesia is a frequently seen complication. The mechanism of headache is intracranial hypotension due to cerebrospinal fluid leaking after meningeal traumatization. The headache is typically orthostatic. Cerebral venous thrombosis is a rare disease. The most common clinical symptom is headache. Headache can appear with different characteristic features.
\end{abstract}

Case Report: In the presented case, there was headache that was resistant to treatment and occurred after spinal anesthesia. The patient applied to the emergency service several times, and her complaint was thought to be associated with spinal anesthesia, and she was given treatment in that direction. But, after some scanning and laboratory tests and physical examinations we made, we found that the headache originated from cerebral venous thrombosis.

Conclusion: Headache in a patient with previous spinal anesthesia history can be regarded as secondary to intracranial hypotension. But, as seen in the presented case, other reasons should be investigated if there is progression in the headache and orthostatic of spinal anesthesia associated headache disappears.

Keywords: Headache, cerebral venous thrombosis, spinal anesthesia

Received: 14.05.2013 Accepted: 27.01.2014

\section{ÖZET}

Giriş: Spinal anestezi sonrası başağrısı, sıklıkla karşılaşılan bir komplikasyondur. Başağrısı oluşum mekanizması, meningeal zedelenme sonrası ortaya çıkan beyin omurilik sıvısında kaçağa bağlı intrakranial hipotansiyondur. Ortaya çıkan ağrı tipik olarak ortostatik özelliktedir. Serebral venöz tromboz nadir görülen bir hastalıktır. Kliniğinde en sık görülen semptom başağıısıdır. İzlenen ağıı farklı karakteristik özelliklerle karşımıza çıkabilmektedir.

Olgu Sunumu: Sunulan olguda, spinal anestezi sonrasında ortaya çıkan ve tedaviye dirençli başağrısı yakınması mevcuttur. Hasta, değişik zamanlarda birçok kez acil servislere başvurmuş ve başağrısı şikayeti spinal anesteziye bağlanarak bu yönde tedavi verilmiştir. Ancak incelemelerimiz sonrasında başağrısının, serebral venöz trombozdan kaynaklandığı tespit edilmiştir.

Sonuç: Spinal girişim anamnezi olan kişilerde ortaya çıkan başağrısının, öncelikle intrakranial hipotansiyona sekonder olduğu akla gelebilmektedir. Sunulan olguda görüldüğü gibi, spinal anestezi ile ilişkili başağrısındaki ortostatik özelliğin kaybolması ve ağrıda progresyon ortaya çıkması gibi bulgularda başağrııının ikincil nedenlerinin araştırılması gerekmektedir.

Anahtar Kelimeler: Başağrısı, serebral venöz tromboz, spinal anestezi

Geliş Tarihi: 14.05.2013 Kabul Tarihi: 27.01.2014

\section{Giriş}

Baş ağrısı yakınmasıyla acil servise başvuran hastaların çoğunluğunda, migren ve gerilim tipi baş ağrısı gibi primer baş ağrıları izlenmektedir. Hastaların \%10'unda ise, ikincil bir nedene bağlı baş ağrısı görülmektedir (1). Sekonder baş ağrıları, hipertansiyon, 


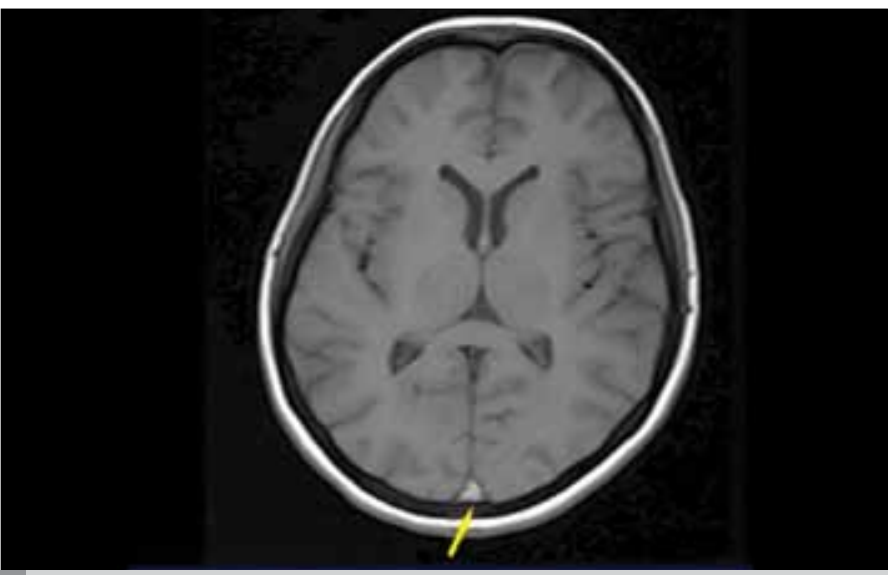

Şekil 1. Beyin MR'da sagital sinüs trombozu izlenmektedir

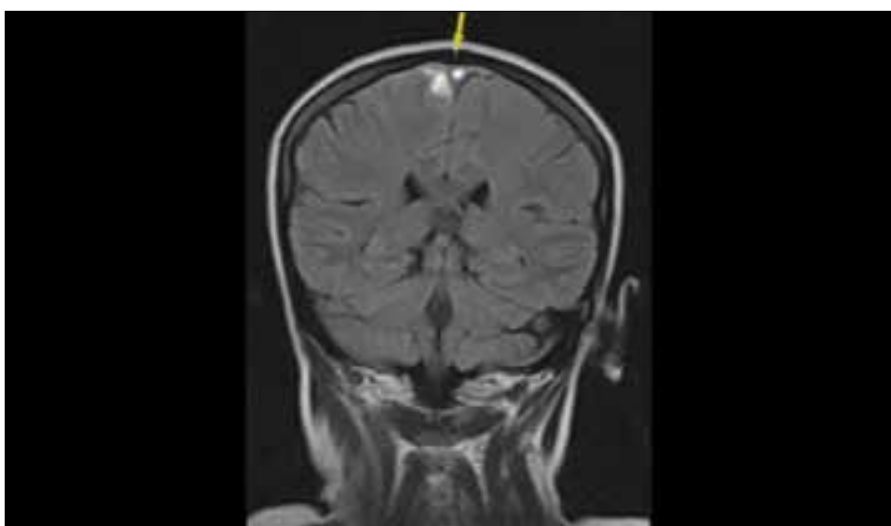

Şekil 2. Beyin MR'da sağ vertekste venöz enfarkt ve süperior sagital sinüste tromboz izlenmektedir

kalp hastalıkları, kulak-burun-boğaz hastalıkları ve göz problemleri gibi ekstrakraniyal nedenlerden kaynaklanabilmektedir. Sekonder baş ağrılarının intrakraniyal nedenleri arasında ise, beyin tümörleri, santral sinir sistemi enfeksiyonları, intrakraniyal kanamalar, iskemik inme, serebral venöz tromboz (SVT) ve intrakraniyal hipotansiyon sayılabilmektedir. İntrakraniyal hipotansiyon spontan olarak ortaya çıkabileceği gibi, lomber ponksiyon (LP), epidural/spinal anestezi, spinal cerrahi gibi spinal girişimler sonrası da gelişebilmektedir. Spinal girişim esnasında oluşabilecek meningeal zedelenmenin, günde 250 mL'den fazla beyin omurilik sıvı (BOS) kaçağına yol açarak, intrakraniyal hipotansiyona neden olduğu düşünülmektedir (2). Intrakranial hipotansiyon baş ağrısı tanısında, ağrının tipik özelliklerinin varlığı önemlidir. Baş ağrısının tipik özellikleri ise, ayağa kalınca artması, yatınca düzelmesi ve çift taraflı olmasıdır.

SVT'de baş ağrısı en sık görülen semptomdur. Bazen baş ağrısı tek bir semptom olarak izlenebilmekle birlikte, bazen de baş ağrısına SVT'nin neden olduğu beyindeki parankim hasarına bağlı fokal nörolojik semptomlar eşlik edebilmektedir. SVT'de görülen baş ağrısının tipik karakteri yoktur. Diffüz nitelikte ve sürekli bir ağrı olabilmekle beraber bazı vakalarda migren baş ağıısını düşündüren, zonklayıcı, tek taraflı, bulantı ve kusmanın eşlik edebileceği niteliktedir. Bazen ani başlayan, çok şiddetli bir ağrı olarak da görülebilmektedir (3).

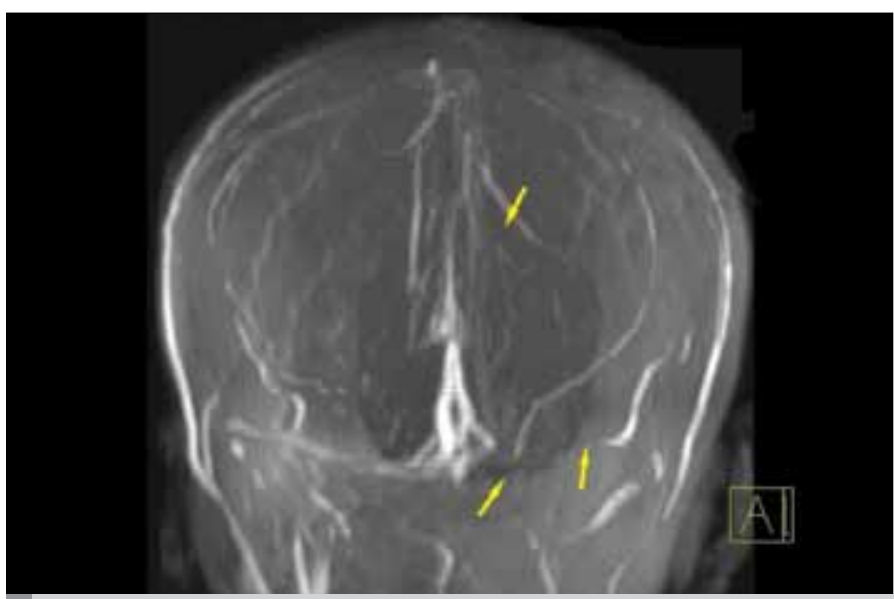

Şekil 3. Beyin venöz MR anjiografide sigmoid sinüs, sagital sinüs ve sol transvers sinüste trombozu gösterir akım kaybı izlenmektedir

Buyazıda, progresif baş ağrısı nedeniyle birçok kez başka acil servislere başvuran ve yakınmasının spinal girişime sekonder intrakraniyal hipotansiyondan kaynaklandığı düşünülen, bize başvurusunda ise SVT tespit ettiğimiz olgu sunulmaktadır. Olgu nedeniyle spinal anesteziden kaynaklanabilecek intraserebral hipotansiyon baş ağrısı ve SVT'ye bağlı baş ağrısını tekrar gözden geçirmeyi amaçladık.

\section{Olgu Sunumu}

Yirmi beş yaşında olan bayan hasta acil servise baş ağrısı şikayeti ile başvurdu. Baş ağrısının, başın tamamına lokalize, şiddetli ve aktiviteyle artan tarzda olduğu, postüral özellik taşımadığı ve ağrıya bulantı, fotofobi ya da sonofobinin eşlik etmediği anlaşıldı. Hastanın iki hafta önce spinal anestezi uygulanarak sezaryen operasyonu ile doğum yapmış olduğu ve baş ağrısının spinal anesteziden bir hafta sonra başladığı öğrenildi. Hasta ağrısının giderek arttığını ve analjeziklere cevap vermediğini, son beş gündür de bulanık görme şikayetinin eşlik ettiğini, son iki gündür ise sol kol ve bacakta uyuşma hissinin başladığını ifade etti. Tıbbi ve ailevi öz geçmişinde herhangi bir özellik olmayan hastada ilaç ve madde kullanım öyküsü yoktu. Fizik muayenesinde, genel durumu iyi ve vital bulguları stabildi. Nörolojik muayenesi normaldi. Göz dibi muayenesinde bilateral venöz pulsasyon izlenmedi. Tam kan sayımı ve metabolik parametreleri içeren laboratuvar incelemelerinde anormal bulgu veya patolojiye rastlanmadı. Kraniyal manyetik rezonans görüntülemede (MRG) sagital sinüste tromboz ve sağ vertekste venöz enfarkt (Şekil 1,2), manyetik rezonans venöz anjiografide ise sigmoid, sagital ve sol transvers sinüste trombozu işaret eden akım kaybı (Şekil 3) izlendi. Baş ağrısının daha önceden teşhis edildiği gibi spinal girişime bağlı olmadığı belirlendi. SVT tanısı konulan hasta nöroloji bölümüne yatırıldı. SVT'ye yönelik antikoagulan tedavi verilen hasta, yatışının 12. günü şifa ile taburcu edildi.

\section{Tartışma}

SVT'nin geçmişte sanıldığından daha sık olduğunu, yeni tanı araçları sayesinde biliyoruz. Hastalığın başlangıcında ve seyrinde izlenen klinik, geniş bir çeşitliliğe sahiptir. Kliniğin çeşitliliği ise tanı ve tedavinin gecikmesine neden olabilmektedir. Hastalık, iki günden 
daha kısa sürede akut olarak başlayabilmektedir. Bunun yanında, otuz günden uzun sürede kronik olarak veya ikisi arasında subakut şekilde ortaya çıkabilmektedir. SVT'de en sık görülen semptom baş ağrısıdır. Baş ağrısının en sık nedeni ise BOS emiliminin bozulması ve/veya venöz oklüzyondan kaynaklanan intrakraniyal basınç artışıdır. SVT'de görülen baş ağrısına farklı semptom ve bulgular eşlik edebilmektedir. İole intrakraniyal basınç artışıyla birlikte, sadece ağrı görülebileceği gibi, baş ağrısı ile beraber hafif uyanıklıktan komaya kadar değişebilen uyanıklık ve bilinç kusurunun görüldüğü diffüz ensefalopati tablosu karşımıza çıkabilmektedir. Bu ağrıda intrakraniyal basınç normaldir. Parankimal hasara bağlı olan fokal nörolojik semptomların da eşlik ettiği ağrı başka bir prezentasyon şeklidir. Akut kavernöz sinüs trombozunda ise, kemozis, propitozis ve oftalmopareziye frontal başağrısı eşlik edebilmektedir (4). Olgumuzdaki klinik, başlangıçta baş ağrısına eşlik eden izole intrakraniyal hipertansiyon şeklinde olup, ilerleyen günlerde parankimal hasarın eklendiği görülmektedir.

SVT'ye yol açabilecek birçok neden vardır ve bu nedenlerden bir kısmı protrombotik durumlardır. Bunlar arasında gebelik, olgumuzda da izlendiği gibi puerperiyal dönem, faktör $\vee$ leiden ve protrombin gen mutasyonları sayılabilmektedir. SVT, oral kontraseptif ve asparjinaz gibi ilaç kullanımları, Behçet hastalığı gibi enflamatuvar hastalıklar, enfeksiyonlar, hematolojik hastalıklar, kanser, dehidratasyon, intrakraniyal hipotansiyon, lomber ponksiyon, spinal anestezi işlemi, juguler kataterizasyon gibi travma ve mekanik nedenlere bağlı olarak da gelişebilmektedir $(5,6)$.

SVT tedavisinin ilk adımı, altta yatan sebeplerin araştırılmasıdır. Tedavi edilebilir nedenler saptanırsa, bunların sağaltımına başlanmalıdır. Kraniyal tomografi veya MRG'de hemorajik lezyon görülse bile sıklıkla SVT'de antikoagulan tedavi verilmektedir(7). SVT'nin semptomatik tedavisinde, nöbetlerin ve baş ağrısının kontrolü ile artmış kafa içi basıncının düzeltilmesi yer almaktadır. Tedaviye erken başlanmasının, mortalite ve morbiditeyi önlemek açısından önemli olduğu bilinmektedir (4).

Intrakraniyal hipotansiyon sıklıkla spontan olarak ortaya çıkmaktadır. Bunun dışında ağır kafa travmaları, lomber ponksiyon, epidural/ spinal anestezi girişimleri, spinal cerrahi gibi sekonder nedenler de intrakraniyal hipotansiyona yol açabilmektedir. Genelde geçici ancak daha nadir olarak kalıcı olabilen baş ağrıları görülebilmektedir. BOS basıncının düşmesi beynin aşağı yönde yer değiştirmesine neden olarak, köprü venler ve duyusal sinirler gibi ağrıya duyarlı yapıların itilmesineyolaçmaktadır.Bu durumda safortostatikveya ağırlıklıolarak ortostatik nitelikte baş ağrıları ortaya çıkmaktadır (8). İntrakraniyal hipotansiyona bağlı baş ağrısı ayakta durmakla ya da oturmakla ortaya çıkan ve yatınca düzelen postüral bir karakterdedir. Baş ağrısına bulantı, kusma, baş dönmesi, çift görme, fotofobi, sonofobi, bulanık görme ve boyun kaslarında sertlik eşlik edebilmektedir . Intrakraniyal hipotansiyon tedavi edilmezse, subdural hematom, kranial sinir parazileri, SVT gibi komplikasyonlar ortaya çıkabilmektedir $(9,10)$. Intrakraniyal hipotansiyonda gadoliniumlu kraniyal MRG önemli bir tanısal testtir. Görüntülemelerde intrakraniyal hipotansiyonun karakteristik özellikleri, pakimeningealde diffüz kalınlaşma ve kontrast tutulması, subdural sıvı birikimleri veya hematom ve beynin aşağı yer değiştirmesine ait bulgulardır (4). Baş ağrısı genelde Sıvı alımı, yatak istirahati ve kafein verilerek düzeltilebilmekle beraber, kronikleşirse kan yaması yapılabilmektedir. Ağrı ortostatik özelliğini kaybettiğinde subdural hematom ya da SVT'nin ortaya çıkmış olabileceği akılda tutulmalıdır.

Olgumuzdaki baş ağrısının, spinal anestezi öyküsü nedeniyle, ilk aşamada intrakraniyal hipotansiyona bağlandığı görülmektedir. Ancak, intrakraniyal hipotansiyona sekonder olan baş ağrısının büyük çoğunluğu, spinal girişimden sonraki ilk günlerde ortaya çıkmaktadır. Hastamızdaki ağrı, spinal anesteziden bir hafta sonra başlamıştır ve postüral nitelik göstermemiştir. Siegle JH.ve arkadaşlarının, spinal anestezi sonrasında gelişen SVT'yi sunduğu olguda izlendiği gibi, ağrı tedaviye direnç göstermiş ve progresif seyretmiş̧ir (6). Tüm bu nedenlere ilave olarak, muayenede intrakraniyal basınçartışının ilkgöz bulgusu olan venöz pulsasyonun kaybolması da başka etyolojilere yönelmeyi gerektirmiştir. Hastamızın puerperiyal dönemde olması ve spinal anestezi geçirmesi, SVT'den şüphelendirmiş ve ileri incelemeler yapılmıştır.

\section{Sonuç}

Acil servise baş ağrısı ile gelen, spinal /epidural anestezi öyküsü olan hastalarda baş ağrısının niteliğini değerlendirmek önemlidir. Acil hekimleri bu konuda SVT'nin bulgularını da hatırlamalı ve bu hastalara yaklaşımda dikkatli olmalıdır.

Informed consent: Written informed consent was obtained from the patient who participated in tis study.

Peer review: Externally peer-reviewed.

Author contributions: Concept - F.D., F.K.; Design - F.D.; Supervision - F.D., F.K.; Materials - F.D.; Data Collection and/or Processing - F.D.; Analysis and/or Interpretation - F.D.; Literature Review - F.D.; Writer F.D.; Critical Review - F.D., F.K.

Conflict of interest: The authors declare no conflict of interest.

Financial Disclosure: The authors declared that this study has received no financial support.

Hasta Onamı: Yazılı hasta onamı bu çalışmaya katılan hastadan alınmıştır

Hakem değerlendirmesi: Dış bağımsız.

Yazar Katkıları: Fikir - F.D., F.K.; Tasarım - F.D; Denetleme - F.D., F.K.; Malzemeler - F.D.; Veri toplanması ve/veya işlemesi - F.D.; Analiz ve/ veya yorum - F.D.; Literatür taraması - F.D.; Yazıyı yazan - F.D.; Eleştirel inceleme - F.D., F.K.

Çıkar Çatışması: Yazarlar herhangi bir çıkar çatışması bildirmemişlerdir. 
Finansal Destek: Yazarlar bu çalışma için finansal destek almadıklarını beyan etmişlerdir.

\section{Kaynaklar}

1. Franksson C, GordtT. Headache after spinal anaesthesia and a technique for lessening its frequency. Acta Chir Scand 1946; 94: 443-54.

2. Peters KS. Secondary headache and head pain emergencies. Prim Care. 2004; 31: 381-93. [CrossRef]

3. de Bruljin SF, Stam J, Kampelle U. Thunderclap headache as first symptom of cerebral venous sinus thrombosis. For the CVST Study Group. Lancet 1996; 348: 1623-5. [CrossRef]

4. de Bruijn SF1, de Haan RJ, Stam J. Clinical features and prognostic factors of cerebral venous sinus thrombosis in a prospective series of 59 patients. J Neurol Neurosurg Psychiatry 2001; 70: 105-8. [CrossRef]
5. Stam J. Trombosis of the cerebral veins and sinuses. N Engl J Med 2005; 352: 1791-8. [CrossRef]

6. Siegle JH, Dewan DM, James FM 3rd. Cerebral infarction following spinal anesthesia for cesarean section. Anesth Analg 1982; 61:390-2. [CrossRef]

7. Einhaupl K, Stam J, Bousser MG, De Bruijn SF, Ferro JM, Martinelli I, et al. EFNS guideline on the treatment of cerebral venous and sinus thrombosis in adult patients. Eur J Neurol 2010; 17: 1229-35. [CrossRef]

8. Silberstein SD, Lipton RB, Goadsby PJ. Headache in Clinical Practice. Second edition. Editörler Türkçe Çeviri: Ertaş M, Akman-Demir G. Klinik Uygulamada Başağrısı. İkinci baskı, Yelkovan Yayıncılık, İstanbul, 2004.

9. T Kansu, S Inci. Spontaneous Intracranial Hypotension without Orthostatic Headache. Türk Nörol Derg. 2009; 15: 35-8.

10. Berroir S, Grabli D, Heran F, Bakouche P, Bousser MG. Cerebral venous sinus thrombosis in two patients with spontaneous intracranial hypotension. Cerebrovasc Dis 2004; 17: 9-12. [CrossRef] 